\title{
Design of an experimental device for preheating combustion air
}

\author{
Lucia Martvoňová ${ }^{*}$, Mária Polačiková ${ }^{1}$, Juraj Drga $^{1}$, and Alexander Backa ${ }^{1}$ \\ ${ }^{1}$ University of Zilina, Department of mechanical engineering, Department of power engineering, \\ Zilina, Slovakia, Univerzitná 8215/1 01026, Zilina, Slovakia
}

\begin{abstract}
The principle of the proposed device is to use part of the waste heat, which otherwise leaves through the chimney unused into the air, to preheat the combustion air. reducing chimney losses and preheating the combustion air will increase the efficiency of the heat source. the device is actually a gravity loop heat pipe with an evaporating part located behind the furnace and a condensing part in the combustion air supply duct. Heat transfer is realized by means of phase transformation of the working medium in the proposed device.
\end{abstract}

\section{Introduction}

Fireplace inserts as a heat source produce heat output by burning fuel. In the form of flue gases, a large amount of waste heat is released through the chimney into the air, which also reduces the efficiency of the fireplace insert itself [1]. It is possible to remove part of the heat from the flue gas, which can be used for water heating [2]. When using these applications, it can be a problem to ensure the safe operation of the fireplace insert in the system and therefore it is necessary to include safety elements such as safety valves, expansion vessels, etc. Another disadvantage is the need for storage tanks, which not only take up space but also increase investment costs. The most advantageous solution therefore seems to be the use of waste heat directly in the combustion processes.

\subsection{Loop Thermosyphon}

Loop thermosyphons are passive heat transfer devices using phase transformation with almost negligible heat loss. The appropriate combination of the working medium used and the construction packaging defines the operating temperature range of the heat pipes [3].

Heat pipes have proven to be an effective solution especially in high temperature applications and insulation, where there is any combination of uneven heat load, limited air flow through the heat generating components as well as space or weight constraints. The loop thermosyphon is used to transfer heat over relatively long distances without additional mechanical devices. The advantage is also flexibility in a limited space and the ability to work in all working conditions [4].

\footnotetext{
* Corresponding author: lucia.martvonova@,fstroj.uniza.sk
} 
This type of heat pipe can only work in the position of the condenser above the evaporator. The movement of the working substance from the condenser to the evaporator occurs due to the weight of the working substance. The inner surface of the heat pipe is smooth and does not contain a capillary structure. The amount of working substance must be sufficient for perfect wetting of the evaporator walls, but not too large due to the formation of bubble boiling in the evaporator [5].

\section{Equipment to increase the efficiency of the fireplace insert}

Important factors for calculating the efficiency of a fireplace insert include the combustion air temperature and the flue gas temperature. By inserting a heat pipe with a closed loop into the fireplace insert system, we can use part of the heat escaping in the form of flue gases to preheat the combustion air. By removing part of the heat from the flue gas, the chimney losses are reduced and by transferring this heat through the heat pipe, the combustion air is heated, which also reduces the need for fuel.

When designing the device, we used the construction of the fireplace insert: FIG.1. The evaporating part of the heat pipe is located in front of the chimney mouth, where it removes heat from the flue gas, which is transferred in the form of saturated steam through a steam pipe to a condenser located in the combustion air supply channel. Due to the location of the condenser above the evaporator, a loop thermosyphon was used, where the working medium can move under its own weight.
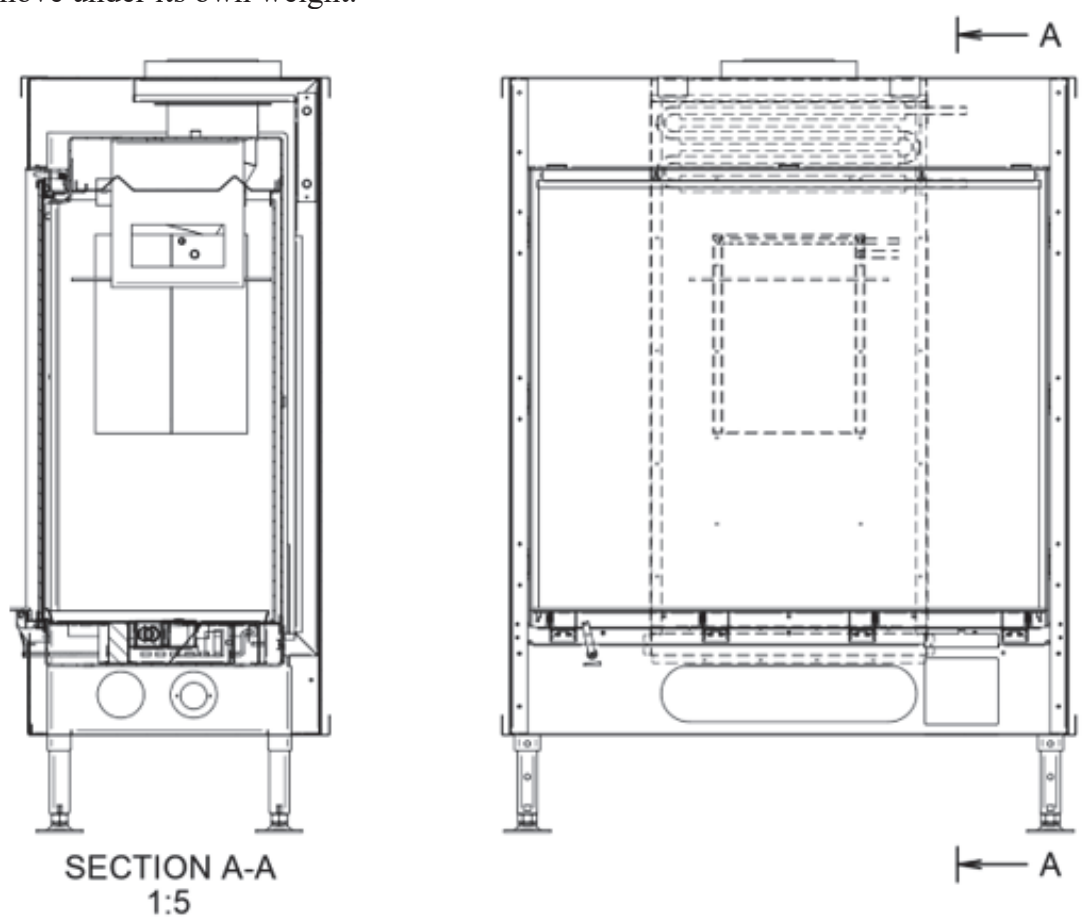

Fig. 1. Placement of a loop thermosyphon in the fireplace insert. 
FIGURE 2. shows the dimensioned external dimensions of the evaporator together with the dimensions relating to the location of the evaporator relative to the condenser. Due to the atypical chimney of the used fireplace insert, we had to adjust the duct for flue gas discharge from the evaporator space.

In addition to the design, the correct choice of heat pipe material and working medium. The material of the heat pipe must be subject to several conditions and, in addition to the required high thermal conductivity, compatibility with the working medium must also be ensured [6]. At the same time, the device must not corrode and must withstand higher chimney temperatures. The ideal combination for this application is the use of copper as a wall material and water as a working medium. The results of chemical and metallographic tests show that copper and water are compatible. The release of inert gases occurred only with the use of surfactants to improve the wettability of the copper capillary systems and with the incorrect removal of the residues of these substances.
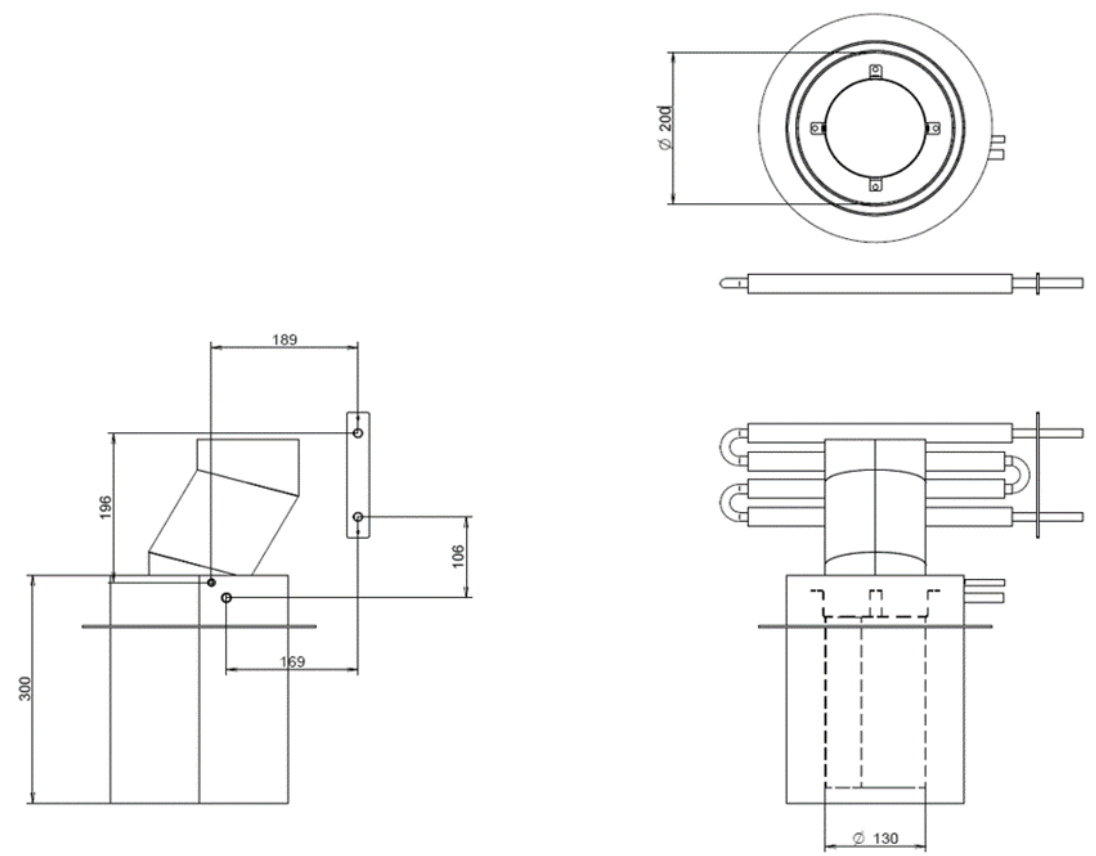

Fig. 2. Dimensions of the device to increase the efficiency of the fireplace insert.

\subsection{Evaporator}

By placing the evaporator at the chimney inlet, we can use the largest amount of heat from the flue gas. In order to prevent the flow of flue gases through the center of the evaporator, we placed a deflector in the evaporator: FIG. 3. It directs the flow of flue gases so that they bypass the inside of the evaporator. By reducing the cross-section, the flue gas flow rate will also increase, which will also give us a higher Reynolds number and a higher heat transfer between the flue gas and the evaporator.

Due to the direct contact of the evaporator with the flue gases, we chose stainless steel as a material, which is also compatible with the working medium, water. 


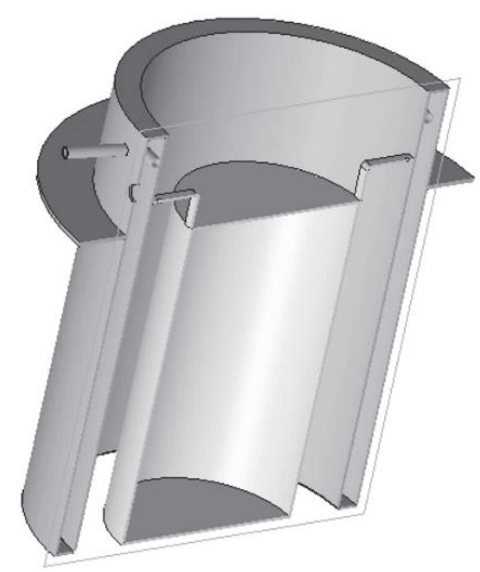

Fig. 3. Evaporator and deflector cut.

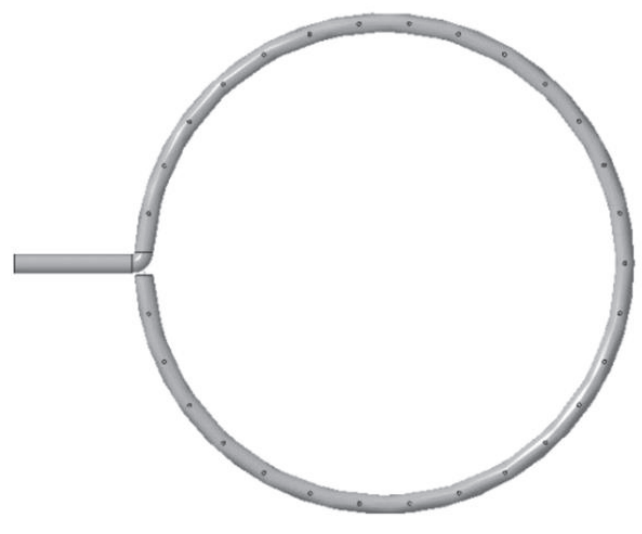

Fig. 4. Distribution pipe.

In order to use the full potential of the evaporator through the distribution pipe: FIG. 4. with 30 holes with a diameter of $1.5 \mathrm{~cm}$ evenly distributed around its circumference, condensate is supplied. If condensate flows into the evaporator only directly from the condensing line, it could happen that the condensate is concentrated in only one part of the evaporator and the condensate does not evaporate evenly.

\subsection{Condenser}

The condenser has been designed according to the combustion air supply duct in which it will be located. The wall material of the condenser is the same as for the heat pipe, i.e. copper. In order to ensure a higher heat transfer between the condenser and the supply air, we used rolled aluminum fins: FIG. 5 .

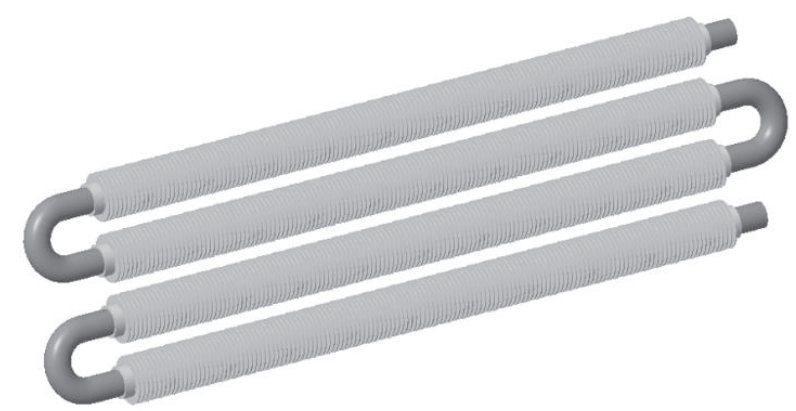

Fig. 5. Condenser.

\subsection{Evaporator and condenser cooperation}

The principle of the loop thermosyphon: Fig. 1 consists in the phase transformation of the working substance. In our case, the water in the evaporator is heated by heat from the flue gas until it reaches the boiling point and changes to steam. Due to the lower density of steam, it spontaneously flows further into the condenser located above the evaporator through a 
steam pipe with a diameter of $12 \mathrm{~mm}$, where it transfers the heat obtained and turns it back into a liquid. Due to its own weight, the condensed steam flows through an $8 \mathrm{~mm}$ diameter condensing pipe, which is connected to a distribution pipe for even condensate flow into the evaporator and the cycle is repeated. Thanks to this natural flow, it is not necessary to include a pump or capillary structure in the system to get the condensate back into the evaporator.

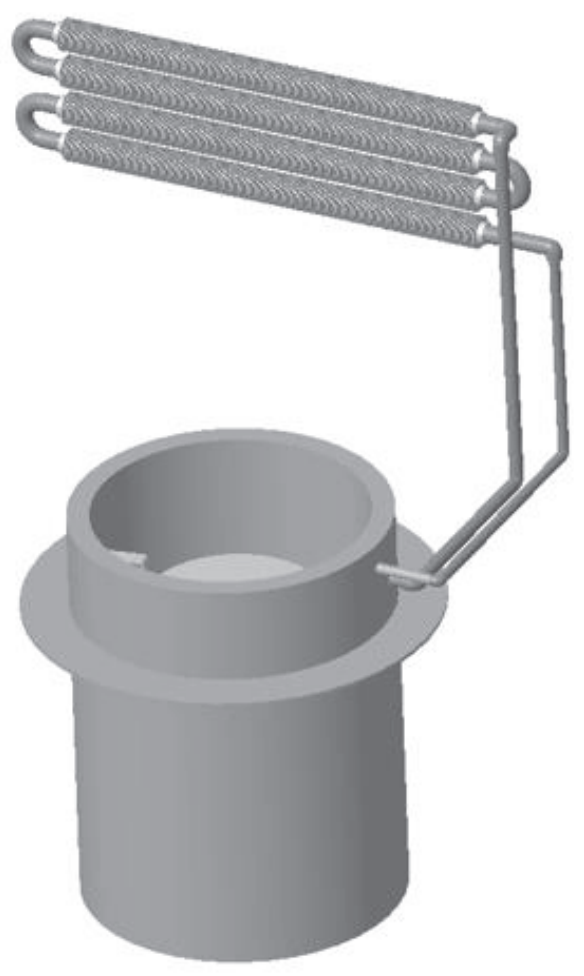

Fig. 6. Condenser and evaporator connection.

Despite the relatively simple construction of this loop thermosyphon, a higher demand for vacuum tightness can be a disadvantage in production. However, the device constructed in this way is low-maintenance, which is a great advantage today.

The device constructed in this way is automatic and in the case of shutting down the fireplace insert, the supply of heat for heating the working substance is interrupted, which gradually stops the phase transformation in the heat pipe. If, on the other hand, there was too much heat transfer between the flue gas and the evaporator and the condenser could not remove the heat obtained by the evaporator, the pressure in the heat pipe would gradually increase, which would also increase the boiling point. Thanks to this natural cycle, it is not necessary to include a large number of safety elements in the system, nor is there a need for an accumulation tank. 


\section{Conclusion}

Increasing the efficiency of heat sources by improving the combustion process is slowly reaching its limits, so we must focus on other possible solutions. Only by using part of the heat from the flue gas to heat hot water can we reduce chimney losses, which have a great impact on the efficiency of the heat source. However, if we use this heat to preheat the combustion air, we can significantly increase the efficiency of the heat source.

In the case of fireplace inserts with solid fuel combustion, a more significant increase in efficiency is expected; when burning solid fuels, chimney temperatures reach higher values than when burning gaseous fuel.

The device with a heat pipe with a closed loop also opens up possibilities for increasing the efficiency of already standing fireplace inserts and small heat sources, where with a relatively small investment we can easily increase the efficiency of a heat source for heating.

This work was supported by projects KEGA 033ŽU-4/2018 Heat sources and environmental pollution and APVV-17-0311 "Research and development of waste-free technology for decomposition and selection of undesirable components from the process gas generated by the gasifier".

\section{References}

1. R Nosek, M Holubčík. Energy properties of air dry firewood. Acta Facultatis Xylologiae Zvolen, 58/1, 105-112 (2016)

2. R Nosek, M Holubčík, Š Papučík. Emission Controls Using Different Temperatures of Combustion Air, Scientific World Journal, 487549 (2014)

3. Nemec, P. - Caja, A. - Lenhard, R. (2009) Analysis of heat transfer limitation of wick heat pipe, Conference: International Conference on Experimental Fluid Mechanics Location: Liberec, CZECH REPUBLIC, EXPERIMENTAL FLUID MECHANICS 2009, PROCEEDINGS OF THE INTERNATIONAL CONFERENCE Pages: 230235

4. Novomestský, M. - Kapjor, A. - Papučík, Š. - Siažik, J. (2016) Heat pipe thermosyphon heat performance calculation Conference: THE APPLICATION OF EXPERIMENTAL AND NUMERICAL METHODS IN FLUID MECHANICS AND ENERGY 2016: XX. Anniversary of International Scientific Conference

5. HLAVAČKA, V., POLÁŠEK, F. a ŠTULZ, P. a ZBOŘIL, V., 1990. Tepelné trubice v elektrotechnice. 1. Vyd. Praha: STNL - Nakladatelství technické literatúry. ISBN L25B3-IV-4/52783.

6. Lenhard, R. - Kaduchová, K. - Papučík, Š.(2014) Analysis of the fill amount influence on the heat performance of heat pipe. [online], 1608(1), 146-152 [cit. 2020-09-07]. ISSN 0094-243X. 